\title{
Erratum
}

\section{Erratum: Postoperative nutrition practices in abdominal surgery patients in a tertiary referral hospital Intensive Care Unit: A prospective analysis}

In the article, "Postoperative nutrition practices in abdominal surgery patients in a tertiary referral hospital Intensive Care Unit: A prospective analysis", published in the pages 319-322, issue 6, vol. 20 of Indian Journal of Critical Care Medicine $^{[1]}$, the third author name is written incorrectly as "B. J. Anil" instead of "Anil Bangalore Gopal,".

Additionally, in the "How to cite this article" section the third author name is written incorrectly as "Anil BJ" instead of "Gopal AB". Thus the correct information in the section should be as following:

Murthy TA, Rangappa P, Gopal AB, Jacob I, Rao K. Postoperative nutrition practices in abdominal surgery patients in a tertiary referral hospital Intensive Care Unit: A prospective analysis. Indian J Crit Care Med 2016;20:319-22.

\section{Reference}

1. Murthy TA, Rangappa P, Anil BJ, Jacob I, Rao K. Postoperative nutrition practices in abdominal surgery patients in a tertiary referral hospital Intensive Care Unit: A prospective analysis. Indian J Crit Care Med 2016;20:319-22.

DOI: $10.4103 / 0972-5229.188216$ 